\title{
Rainfall area identification using satellite data
}

\author{
Marcela H. González*, Inés Velasco \\ Department of Atmospheric Sciences, Universidad de Buenos Aires, 1428 Buenos Aires, Argentina
}

\begin{abstract}
A technique is presented for determining rainfall areas through the simultaneous use of infrared and near-infrared satellite data. These data are a reduced-resolution version of the original AVHRR (Advanced Very High Resolution Radiometer) images from the satellite NOAA-12. The scheme developed was used in order to differentiate among clear sky (or with very few clouds present), raining clouds and non-raining clouds for a mid-latitude region over A.rgentina. The scheme was developed by applying clustering and discriminant analysis to the maxima obtained from 2-dimensional histograms in the infrared and near-infrared domain. Warm-season data during daylight hours were used to develop and test the scheme. It was tested on 9 dates, and comparison of the classification results with reports from ground stations was encouraging.
\end{abstract}

KEY WORDS: Satellite A AVHRR images · Cloud classification - Rainfall - Clustering analysis - Rainfall areas - Discriminant analysis

\section{INTRODUCTION}

The use of satellite imagery is of great importance in meteorology and climatology applications. The present network for rainfall monitoring around the world by conventional means is deficient in many areas, especially if rainfall data are required in 'near real time', because many rain gauges generally provide data on a daily or monthly basis. Important short-term or nearreal-time uses of rainfall data are found in weather forecasting, river management and flood control because they complement conventional data in space and time. The density of rain gauges is often too low, especially over oceanic and arid regions. Satellite systems provide spatially continuous coverage of data in large areas, in contrast to those obtained from surface weather observations. Various types of instruments are used for delineating rainfall areas, such as rain gauges, radars and satellite-borne sensors. Weather radars are costly and are unavailable in a number of countries. Because of this, the use of satellite data to delineate rain areas has become a technique of great interest to meteorologists. As satellites observe the atmosphere from above, they provide information on cloud coverage and on different types of soil and water. The satel-

\footnotetext{
•E-mail: gonzalez@meteor.uba.ar
}

lite sensors measure reflected solar and emitted radiation from the clouds. Different atmospheric 'windows' (wavelength ranges) are used in order to determine reflected or emitted radiation. Most cloud information is provided by measurements in the infrared window and visible window. The visible data relate most strongly to the albedo of the target, so that highly reflective surfaces such as those of ice, snow, sand or clouds are bright in visible images. The infrared data are related to the black-body temperature of the target: cloud tops at different levels have different brightnesses (temperatures) in the infrared. The 2 bands, taken together, almost solve the problem of cloud type recognition. It is important to note the disadvantage of using visible data since they are not available during nighttime.

The problem of rainfall estimation from satellite data has been studied by many authors applying different methods and different data. A complete review of the available techniques for the estimation of rainfall from satellite-derived visible and infrared data has been given by D'Souza et al. (1990). In cloud type recognition using only visible and infrared window channels, it is possible to determine cloud-free areas and rainfallcloud coverage. The development of statistical methods to extract the maximum amount of information from satellite images permits a better understanding of the properties of the clouds. 
Image data from polar-orbiting satellites are used to classify different types of clouds, but these satellites provide only 1 or 2 images per day. Geostationary satellites have the advantage of providing highly repetitive data and therefore the development and evolution of a precipitating system can be analyzed; however, this information is not available in certain regions. The spatial resolution provided by these 2 kinds of satellites is also different. The European METEOSAT satellite has a resolution of $5 \times 5 \mathrm{~km}$ in the infrared channel, and the GOES satellite a resolution of $4 \times 8 \mathrm{~km}$. The use of AVHRR (Advanced Very High Resolution Radiometer) data is preferred for its $1.1 \times 1.1 \mathrm{~km}$ resolution when it is available. It is important to consider that the estimation of rainfall is based on inferences from satellite measurements of radiation and, in some regions of the world, the spatial resolution of today's satellite sensors is finer than the resolution of rain-gauge networks that are used to verify the satellite-based schemes.

Several techniques for rain estimation have been developed in the last $30 \mathrm{yr}$. Some of them are used for climatological purposes and rainfall estimates for a 12 or $24 \mathrm{~h}$ period are made, weighting cloud type and area by local climatology coefficients (Barrett 1970 , 1973, Follansbee 1973). Kilonsky \& Ramage (1976) derived monthly estimates over the Pacific Ocean by relying on the fact that there was a high correlation between the number of days with highly reflective clouds and monthly rainfall. In addition, some techniques have been developed for estimating real-time precipitation. For example, Scofield \& Oliver (1977) and Scofield (1987) examined sequences of half-hourly images from GOES and computed the rainfall in the convective system. Tsonis \& Isaac (1985) developed a method for instantaneous rain-area delineation using GOES data. Seze \& Desbois (1987) found 9 cloud classes using cluster analysis in a 4 -dimensional space - visible, infrared, variance of visible and variance of infrared - and each cluster was associated with one cloud class. Most of the methods are based on the use of visible and infrared channels. Current microwave sensors are useful at all latitudes and over land as well as water (Barrett et al. 1987, Spencer et al. 1989, Negri et al. 1994).

Digital sateliite data are still not normally obtainable in some regions, e.g. Argentina. Consequently, some studies have been done with the little information that is available. For example, the Scofield \& Oliver (1977) technique was adapted by González \& Velasco (1987) to the available satellite data and applied to some convective systems which developed over continental Argentina. As it was not possible to continue receiving GOES data, some attempts were made to use the AVHRR data available. The Tsonis \& Isaac (1985) tech- nique to delineate instantaneous rain areas was modified by Velasco \& González (in press) using nearinfrared and infrared AVHRR data and the scheme was proved successful for some cases in summer 1987. In order to obtain a more objective method for delineating rain areas, the use of both information from the near-infrared and infrared channels and statistical methods involving 2-dimensional histogram partitioning, i.e. cluster analysis and discriminant analysis, is proposed in this paper.

\section{DATA}

The data used in this study were obtained from the National Weather Service (NWS) of Argentina. These archives are the only source of satellite information available in the country. The satellite data found in these archives are a reduced-resolution version of the original AVHRR images from NOAA-12 (Channels 2 and 4). These images have an $8 \times 8 \mathrm{~km}$ resolution and have been transformed into a gnomonic projection. Channel $2(0.725$ to $1.1 \mathrm{\mu m})$ is located in the nearinfrared (NI) portion of the spectrum and Channel 4 $(10.5$ to $11.5 \mu \mathrm{m})$ is located in the thermal infrared (TI) window. The Channel 2 window appears to be suited for cloud analysis (Phulpin et al. 1983, Berger 1989). All the available dates in the NWS archives were used for the afternoon hours during summer 1993 and the verifying dates were randomly selected. NI and TI imagery was used for $20 \mathrm{~d}$ in December 1992 and January, February and March 1993 (Table 1) to classify an area from $30^{\circ}$ to $36^{\circ} \mathrm{S}$ and $56^{\circ}$ to $64^{\circ} \mathrm{W}$, and 9 dates were used to verify the scheme. Fig. 1 shows the area of analysis and the rain-gauge network used for verification on the ground. This area was selected because it has the densest and most homogeneous rain-gauge network of any region in Argentina. A total of 22 sets of records from meteorological stations (containing rainfall and cloudiness data) were available in this area. The rainfall areas identified by the method were checked with the rainfall reports at the time of the satellite pass. The digital images were processed on a PC using the program IDRISI 4.0 (Eastman 1992).

\section{METHODOLOGY AND RESULTS}

\section{A simple classification scheme}

The initial step was to consider a subset of $100 \times$ 80 pixels from each of the images covering the area of interest. A.ll the pairs of afternoon images (NI and TI) available for summer 1993 were used. Various cloud classes represented in the satellite images (considering 
Table 1. Dates and times of satellite images used in this study

\begin{tabular}{|c|c|}
\hline Date & Time (UTC) \\
\hline \multicolumn{2}{|c|}{ Training sample } \\
\hline 22 Dec 1992 & $19: 39$ \\
\hline 30 Dec 1992 & $19: 43$ \\
\hline 5 Jan 1993 & $20: 11$ \\
\hline $7 \operatorname{Jan} 1993$ & $19: 47$ \\
\hline 13 Jan 1993 & $20: 15$ \\
\hline 23 Jan 1993 & $19: 54$ \\
\hline $30 \mathrm{Jan} 1993$ & $20: 10$ \\
\hline 31 Jan 1993 & $19: 58$ \\
\hline 8 Feb 1993 & $20: 02$ \\
\hline 9 Feb 1993 & $19: 50$ \\
\hline 15 Feb 1993 & $20: 18$ \\
\hline 16 Feb 1993 & $20: 06$ \\
\hline 17 Feb 1993 & $19: 54$ \\
\hline 24 Feb 1993 & $20: 10$ \\
\hline 25 Feb 1993 & $19: 58$ \\
\hline 4 Mar 1993 & $20: 13$ \\
\hline 5 Mar 1993 & $20: 01$ \\
\hline 6 Mar 1993 & $19: 49$ \\
\hline 13 Mar 1993 & $20: 05$ \\
\hline 14 Маг 1993 & $19: 53$ \\
\hline \multicolumn{2}{|c|}{ Verifying sample } \\
\hline 6 Jan 1993 & $19: 59$ \\
\hline $14 \operatorname{Jan} 1993$ & $20: 03$ \\
\hline $21 \operatorname{Jan} 1993$ & $20: 19$ \\
\hline 1 Feb 1993 & $19: 47$ \\
\hline 7 Feb 1993 & $20: 15$ \\
\hline 23 Feb 1993 & $20: 22$ \\
\hline 12 Mar 1993 & $20: 17$ \\
\hline 20 Mar 1993 & $20: 21$ \\
\hline 21 Mar 1993 & $20: 08$ \\
\hline
\end{tabular}

clear sky as a cloud class) were differentiated through their bivariate frequency distributions in the NI-TI domain. Tsonis (1984) concluded that the number of peaks in a frequency distribution was an indication of the number of classes that exhibited different spectral characteristics. The digital NI and TI values range from 0 to 255 and the 2-dimensional histograms were derived by dividing these data into 16-unit subranges. For example, Fig. 2 shows the bidimensional histogram for 8 February 1993. The location of the resulting peaks was adjusted by considering the weight of the 8 neighboring frequencies, and the peaks were posi-
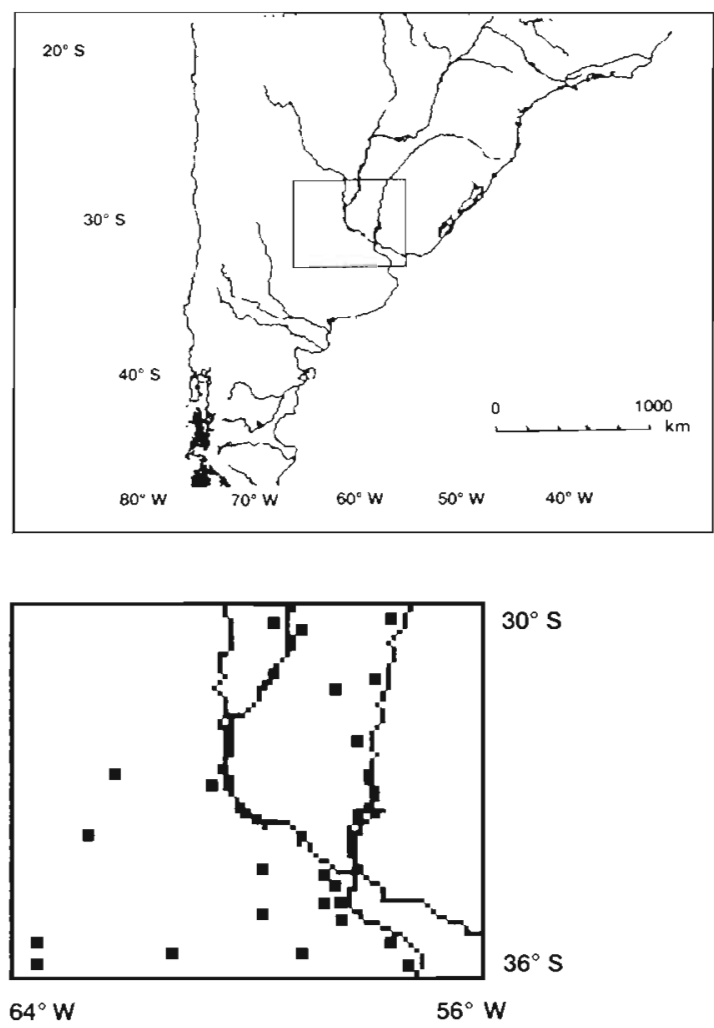

Fig. 1. Area of study and rain-gauge network

tioned in a TI vs NI diagram. Only the peaks whose frequency in the bidimensional histogram was greater than 80 (which is $10 \%$ of the total pixels in the image) were considered in the partition of the NI-TI space (see Fig. 3) and plotted on it. A method was applied in order to separate the peaks into groups, each one with different spectral characteristics corresponding to a special cloud type. The most common procedure for solving this problem is non-supervised partitioning, known as the clustering technique. Clustering methods have the advantage of forming natural data groupings without any prior classification. The applied method starts by considering each point as an individual cluster; then the 2 closest clusters are joined, and the procedure ends when a specified number of clusters have been

\begin{tabular}{|c|c|c|c|c|c|c|c|c|c|c|c|c|c|}
\hline NI TI & $0-15$ & \begin{tabular}{|l|}
$64-79$ \\
\end{tabular} & $80-95$ & $96-111$ & 112-127 & $128-143$ & $144-159$ & $160-175$ & $176-191$ & 192-207 & $208-223$ & $224-239$ & $240-255$ \\
\hline $0-15$ & 2 & 0 & 0 & 18 & 28 & 0 & 0 & 0 & 0 & 0 & 0 & 0 & 0 \\
\hline $16-31$ & 0 & 6 & 53 & 72 & 48 & 9 & 1 & 0 & 0 & 0 & 0 & 0 & 0 \\
\hline $32-47$ & 0 & 10 & \begin{tabular}{|l|}
364 \\
\end{tabular} & 547 & 287 & 151 & 77 & 58 & 7 & 2 & 0 & 0 & 0 \\
\hline $48-63$ & 0 & 0 & 0 & 23 & 86 & 221 & 275 & 253 & 263 & 167 & 22 & 1 & 0 \\
\hline $64-79$ & 0 & 0 & 0 & 0 & 18 & 338 & 473 & 269 & 206 & 347 & 355 & 69 & 0 \\
\hline $80-95$ & 0 & 0 & 0 & 0 & 2 & 100 & 501 & 170 & 90 & 132 & 382 & 648 & 13 \\
\hline $96-111$ & 0 & 0 & 0 & 0 & 0 & 4 & 71 & 42 & 32 & 24 & 81 & 517 & 35 \\
\hline $112 \cdot 127$ & 0 & 0 & 0 & 0 & 0 & 2 & 0 & 8 & 2 & 2 & 1 & 11 & 1 \\
\hline 128-143 & 0 & 0 & 0 & 0 & 0 & 0 & 0 & 0 & 0 & 0 & 1 & 0 & 0 \\
\hline $240-255$ & 0 & 0 & 0 & 0 & 0 & 0 & 0 & 0 & 0 & 0 & 0 & 0 & 2 \\
\hline
\end{tabular}

Fig. 2. Bidimensional histogram for 8 February 1993. Columns and rows containing only zero values have been omitted 


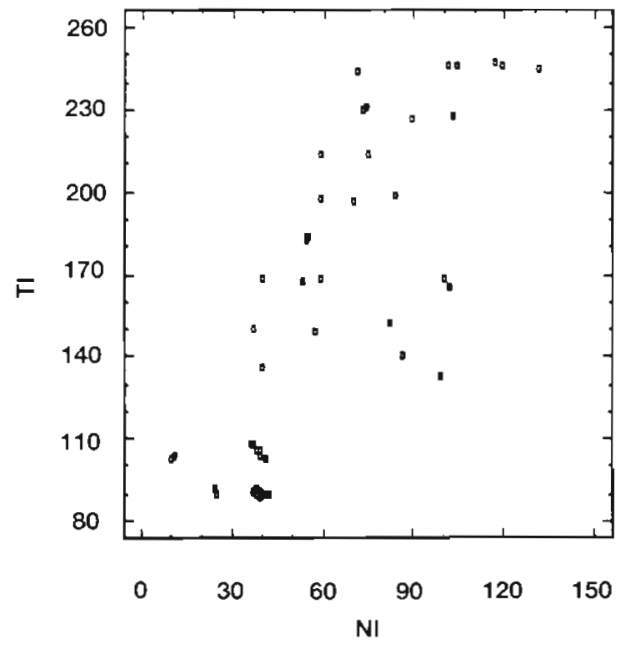

Fig. 3. Peaks from the whole training set positioned in the NI-TI space

generated. There is more than one way to define the distance between 2 clusters but the results are not the same. Let $C_{j}$ and $C_{1}$ be 2 clusters and $d$ the distance between them:

$$
\begin{array}{ll}
d=d_{\text {min }}=\min |x-y| & x \in C_{11} y \in C_{j} \\
d=d_{\text {max }}=\max |x-y| & x \in C_{11} y \in C_{j} \\
d=d_{\text {avg }}=\left(\sum \sum|x-y|\right) /\left(n_{j} n_{j}\right) & x \in C_{i} y \in C_{j} \\
d=d_{\text {mean }}=\left|m_{i}-m_{j}\right| &
\end{array}
$$

where $n_{i}\left(n_{j}\right)$ is the number of points in cluster $C_{i}\left(C_{j}\right)$ and $m_{i}\left(m_{j}\right)$ is the mean of the points of cluster $C_{1}\left(C_{j}\right)$. These algorithms define the nearest neighbor, the furthest neighbor, and the average distance and mean distance respectively. All of these were applied to the set of peaks. When the nearest or the mean algorithm was used, almost all of the points were grouped into 2 major clusters; therefore these algorithms could not discriminate clearly between raining and non-raining clouds. However, the furthest-neighbor algorithm clearly provided 3 clusters, and thus is used in the analysis below. If more than 3 clusters were specified the percentage of coverage of the new clusters would be very small. Table 2 shows the percentage of coverage by each class when different algorithms are used and 3 clusters are specified. Fig. 4 shows the final clusters from the whole training set, when the furthest algorithm was applied

In order to analyze the classes separated by this method, the images were visually inspected. The restituted picture for each pair of images was elaborated and compared to the NI and TI images. Rainfall and cloud reports from 22 ground stations for the particular time of the satellite pass were used to confirm this analysis. Three classes were separated by the algo-
Table 2. Percentage of coverage by each cluster specified using different algorithms for calculating the distance between 2 clusters

\begin{tabular}{|lccc|}
\hline Method & Cluster A & Cluster B & Cluster C \\
\hline Nearest & 10 & 48 & 42 \\
Furthest & 16 & 42 & 42 \\
Average & 54 & 4 & 42 \\
Mean & 48 & 10 & 42 \\
\hline
\end{tabular}

rithm. One of them (Class A) represents a specific kind of cloud: thick, with vertical development, such as nimbostratus and cumulonimbus clouds producing rainfall in the area. A second class represents midlevel clouds, cirrus clouds or edges of large convective masses which do not produce any rainfall (Class B). The last one (Class C) represents clear sky or very few clouds present.

The peaks belonging to Class A correspond to a region of the image with the strongest convection, very bright in NI and cold in TI. On 10 of the 20 days, no

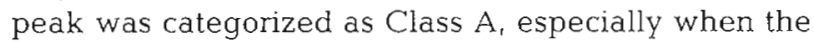
clouds were not organized as a convective system. Whenever some of the stations in the area had reported rainfall (nimbostratus or cumulonimbus) a Class A peak was present, except on 6 March 1993 when no peak was categorized as Class $A$, even though some stations had reported intermittent and/or weak rainfall. In this case the signals were bright and warm because stratus clouds covered the sky.

The peaks belonging to Class $B$ represent the edges of large convective masses or other non-rainfallproducing clouds. In some cases with relatively low temperatures and low brightness, mid-level or cirrus clouds were observed. The variability in NI was due to

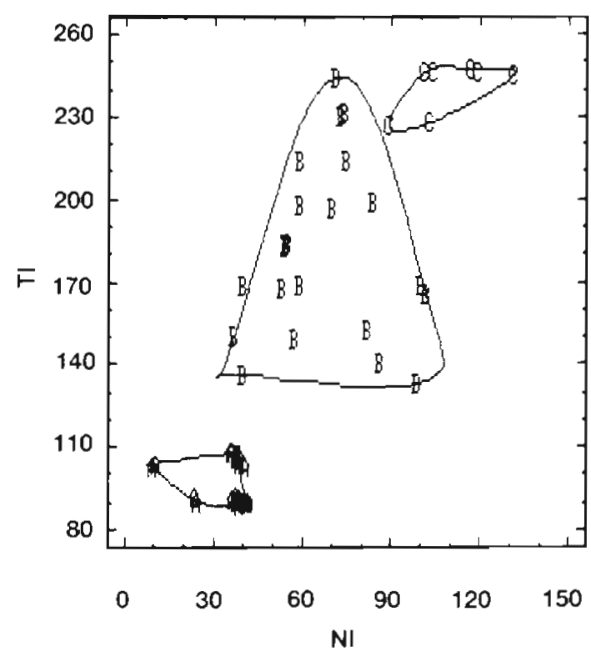

Fig. 4. Cluster analysis of peaks in the $\left(\mathrm{NI}_{t} \mathrm{TI}\right)$ domain 
the differences in albedo between cumulus and stratus clouds, and the classification did not discriminate between these 2 classes.

On some days, there were 2 peaks belonging to Class $C$ in the same image: one with relatively high $\mathrm{TI}$ (low temperature) and relatively low NI (low albedo), and the other with relatively low TI (high temperature) and relatively high NI (high albedo). The first peak respresents the water surface of the Rio de la Plata, and the second, the land. The radiometer measures reflected solar radiation on Channel 2 and this fact allows soil to be distinguished from water in cloud-free areas. When only 1 peak was classified as Class $C$ it was because the river area was overcast or partially cloudy, and therefore the number of pixels over the water without clouds was too small to generate a peak on the 2-dimensional histogram.

When cumulus clouds were smaller than a pixel, they appeared brighter than the ground area, and in this situation the individual cumulus clouds could not be distinguished. It was also necessary to consider that the satellite views the clouds from above and the observer does it from below. Sometimes there are multiple layers of clouds and this makes verification more difficult.

Similar results were obtained by Barrett \& Martin (1981), Henderson-Sellers (1984) and Desbois et al. (1982), who found that raining clouds showed reflectivity values from the visible and infrared channels close to those obtained in this study and identified as Cluster A in Fig. 4. Unfortunately, no test of significance for cluster procedures is currently available (Green 1978).

After cluster analysis, each of the images was reclassified following these criteria:

(1) All pixels with an NI count greater than NI1 and TI count greater than TI1, where (NI1, TI1) are the coordinates of the peaks classified as Class $A$ on that day, were reclassified as covered with vertically developing clouds which produce rainfall.

(2) All pixels with NI count less than NI2 and $\mathrm{Tl}$ count less than TI2, where (NI2, TI2) are the coordinates of the maximum peak classified as Class $C$ over land, were classified as clear sky or sky with very few clouds present.

(3) All other pixels were classified as clouds which could not produce any rainfall.

Fig. 5a shows an example of the reclassification for 23 January 1993, where the white area indicates rainfall-producing clouds; the gray area, non-precipitating clouds; and the black area, clear sky. Fig. 5b shows the infrared image for the same date.

In order to partition the 2-dimensional space objectively, a discriminant analysis was performed (Davis 1973). First, the clear sky (Cluster C) was separated from cloudy sky (Clusters $A$ and B). The line that dis- criminates the 2 groups in the (NI, TI) domain is

$$
\mathrm{TI}=-0.43 \mathrm{NI}+173.19
$$

The results obtained (Table 3) from both methods (discriminant and cluster analysis) revealed a difference at only 4 points classified as cloudy sky (Classes A and $B$ ), representing $13.8 \%$ of the points.

Second, the rainfall-producing clouds (Cluster A) were separated from the non-rainfall-producing clouds (Cluster B). The line that discriminates these 2 groups is:

$$
\mathrm{TI}=-0.49 \mathrm{NI}+248.51
$$

Table 4 shows that all the points in Cluster A were classified identically by both methods.

A Fisher test for the significance of the discriminant function was applied following Davis (1973):

$$
\begin{aligned}
F= & {\left[\left(n_{a}+n_{b}-m-1\right) n_{a} n_{b} D^{2}\right] / } \\
& {\left[\left(n_{a}+n_{b}-2\right) m\left(n_{a}+n_{b}\right)\right] }
\end{aligned}
$$

where $n_{\mathrm{a}}=$ number of points in the first group, $n_{\mathrm{b}}=$ number of points in the second group, $m=$ number of variables, and $D^{2}=$ Mahalanobis' distance (distance measured between the means of the 2 groups). The
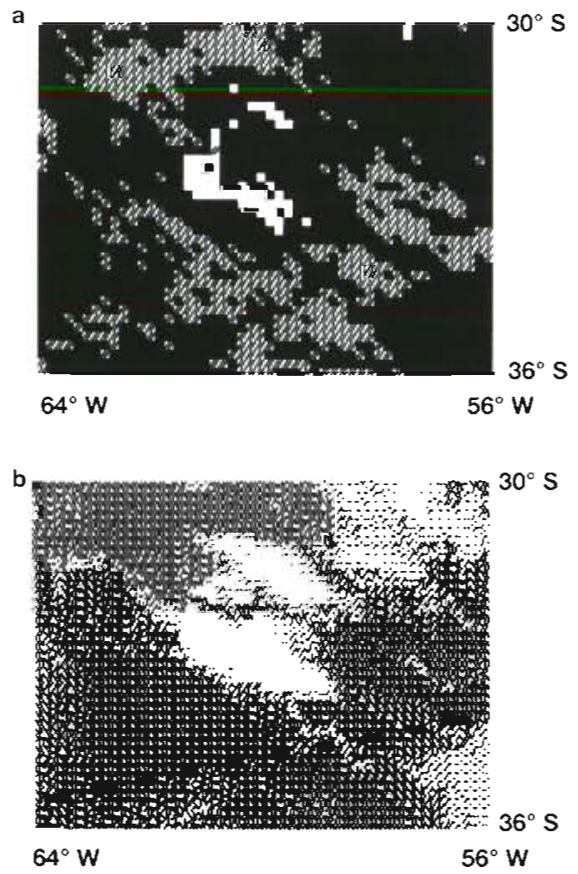

Fig. 5. (a) Reclassification of pixels after cluster analysis, for 23 January 1993. The white area indicates rainfall-producing clouds; the gray area, non-precipitating clouds; and the black area, clear sky. (b) Infrared image for 23 January 1993, with higher values indicated by lighter areas (heavy dashed line is an error in the original satellite image, i.e. pixels with no value) 
Table 3. Comparison of classification results (no. of peaks in each class, percentage) from discriminant analysis and cluster analysis separating clouds from clear sky

\begin{tabular}{lcc} 
& Group from discriminant analysis: \\
& C and B \\
\hline Cluster: & & \\
C & 23,100 & 0,0 \\
A and B & $4,13.8$ & $25,86.2$ \\
\hline
\end{tabular}

Table 4. Comparison of classification results (no. of peaks in each class, percentage) from discriminant analysis and cluster analysis separating raining clouds from non-raining clouds

\begin{tabular}{|c|c|c|}
\hline & \multicolumn{2}{|c|}{ Group from discriminant analysis: } \\
\hline & A & B \\
\hline \multicolumn{3}{|c|}{ Cluster: } \\
\hline A & 11,100 & 0,0 \\
\hline B & $4,22.2$ & $14,70.8$ \\
\hline
\end{tabular}

degrees of freedom are $\left(n_{\mathrm{a}}+n_{\mathrm{b}}-m-1\right)$ and $m$. The null hypothesis tested by this statistic is that the distance between the groups is zero. The application of this test to the 2 discriminant lines described earlier shows that the discrimination was satisfactory with a $95 \%$ confidence level.

Fig. 6 shows solid lines that discriminate the (NI, TI) domain using the whole training set. These lines are decision boundaries, and every point in a given space automatically becomes associated with the class that corresponds to each cluster: Class A (Sector pp), Class B (Sector $\mathrm{n} n$ ) and Class $C$ (Sector $\mathrm{CC}$ ). The dashed lines are boundaries generated using the training and the verifying samples together. It is clear that the inclusion of more data does not modify the scheme significantly.

\section{Verification of the scheme}

In order to delineate areas in which rain was occurring, the bidimensional frequency histogram was derived for each of the verifying dates and the resulting peaks were positioned in the partitioned space. If there were no peaks in Sector pp, all pixels in the image were assigned the value 'no rain'. If there was a peak in Sector pp with coordinates (NI1, TI1), all pixels in the image with NI greater than NI1 and TI greater than TI1 were considered 'raining' points.

On 1 and 23 February and 20 and 21 March no peak was positioned in Sector pp. This result indicated that it was not raining in the area on those days, and in fact no rainfall was reported at any of the stations in the area.

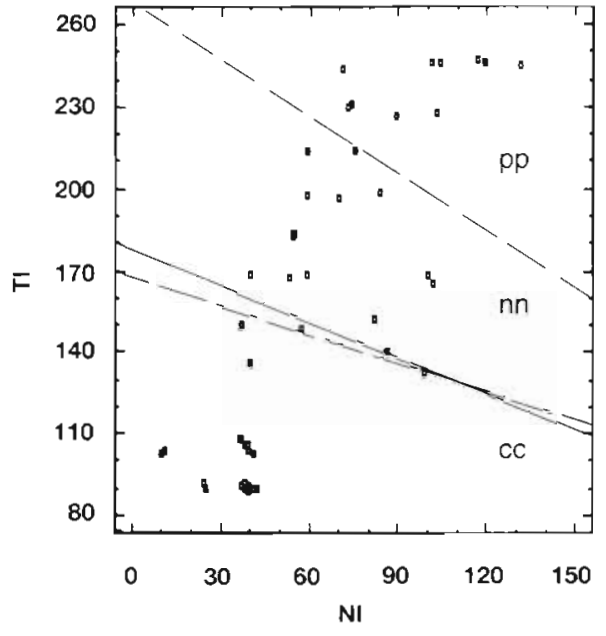

Fig. 6. The NI-TI space partitioned into sectors using discriminant analysis

On 6 January (Fig. 7a), 12 March (Fig. 8a), 14 January (Fig. 9a), 21 January (Fig. 10a) and 7 February (Fig. 11a), 1 peak was positioned in Sector pp and therefore a rain area was delineated by the method. Figs. $7 \mathrm{~b}$ to $11 \mathrm{~b}$ show the infrared images for these dates.

Some of the statistics defined by Tsonis (1988) were used to evaluate the efficiency of this technique:

Probability of rainfall detection: $\mathrm{POD}=R_{\mathrm{r}} /\left(N_{\mathrm{r}}+R_{\mathrm{r}}\right)$

False alarm ratio: FAR $=1-R_{\mathrm{r}} /\left(R_{\mathrm{n}}+R_{\mathrm{r}}\right)$

Percent error: $f=\left(N_{\mathrm{r}}+R_{\mathrm{n}}\right) /\left(N_{\mathrm{n}}+N_{\mathrm{r}}+R_{\mathrm{r}}+R_{\mathrm{n}}\right)$

where $N_{n}=$ the number of stations correctly classified as no-raining points, $N_{\mathrm{r}}=$ the number of stations incorrectly classified as no-raining points, $R_{n}=$ the number of stations incorrectly classified as raining points, $R_{\mathrm{I}}=$ the number of stations correctly classified as raining points.

POD shows the ability of the scheme to detect the points where it is raining; 1 is a perfect value. FAR indicates the possibility of detecting rainfall where there is no rain and has a perfect value of 0 . $f$ shows the error in detecting pixels with or without rain.

The statistics calculated for dates on which rain occurred are shown in Table 5. The results obtained for the 9 verifying dates were encouraging.

\section{SUMMARY AND CONCLUSIONS}

This paper has presented a technique to determine areas of rainfall using simultaneous near-infrared and infrared data obtained from the NOAA-12 satellite. Although most previously developed bi-spectral 

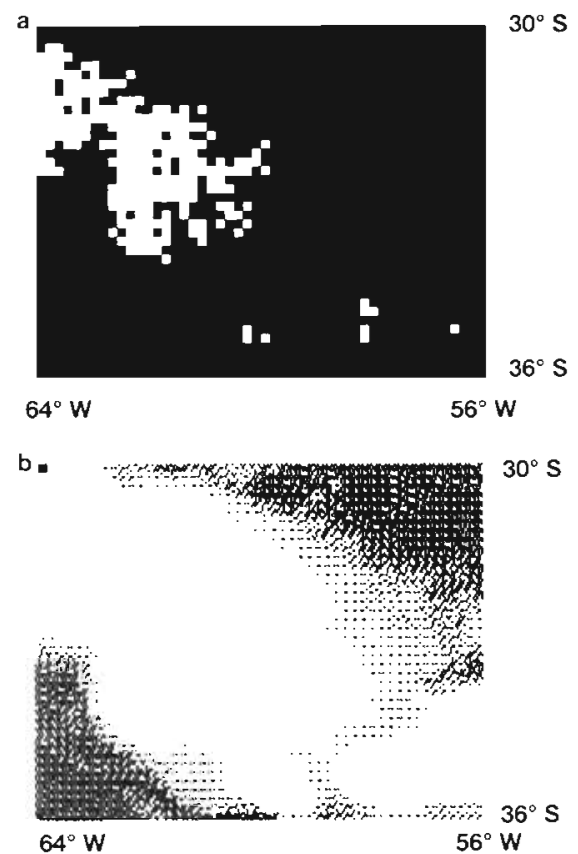

Fig. 7. (a) Rain area (white) as classified by discriminant analysis for 6 January 1993. (b) Infrared image for 6 January 1993, with higher values indicated by lighter areas
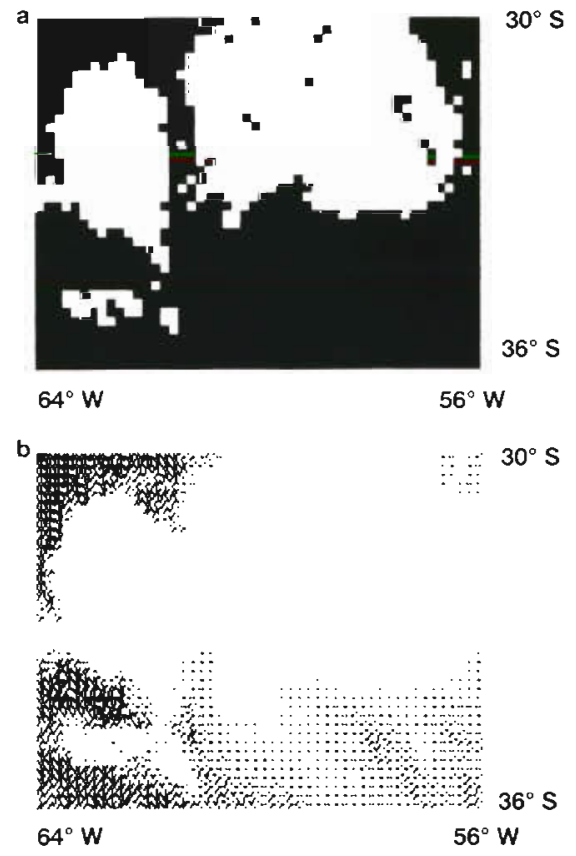

Fig. 8. (a) Rain area (white) as classified by discriminant analysis for 12 March 1993. (b) Infrared image for 12 March 1993, with higher values indicated by lighter areas

methods use visible and infrared bands, the band captured by Channel 2 (N) appears suited to cloud analysis when the visible band is not available or when extensive water surfaces are present in the area of analysis. The technique involved applying cluster
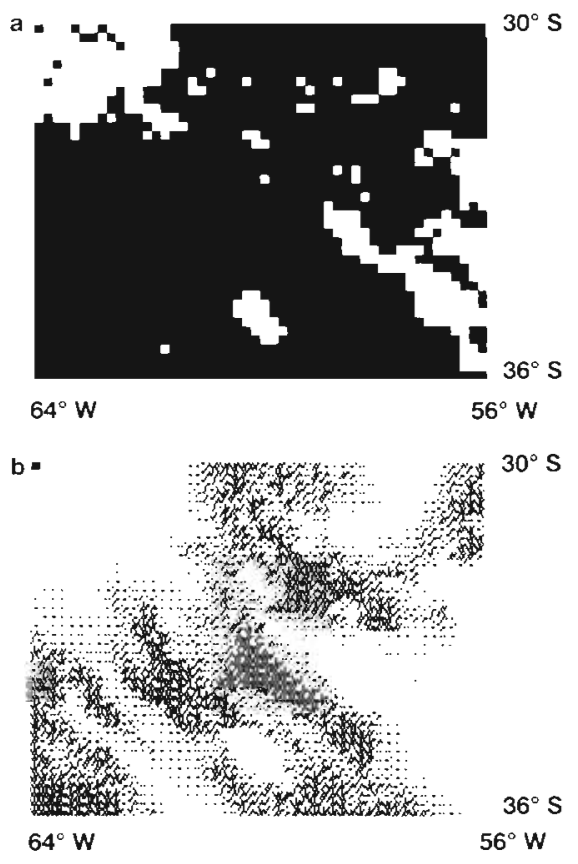

Fig. 9. (a) Rain area (white) as classified by discriminant analysis for 14 January 1993. (b) Infrared image for 14 January 1993, with higher values indicated by lighter areas
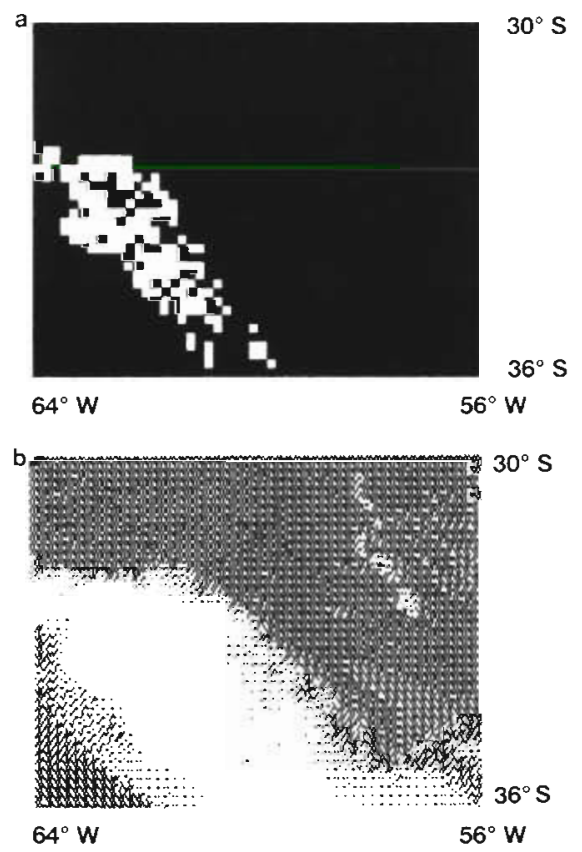

Fig. 10. (a) Rain area (white) as classified by discriminant analysis for 21 January 1993. (b) Infrared image for 21 January 1993, with higher values indicated by lighter areas

and discriminant analysis to the maxima obtained from bidimensional histogram values plotted on the (NI, TI) domain. Cluster analysis techniques are best used for preclassification, and afterwards a classification methodology such as discriminant analysis can be 


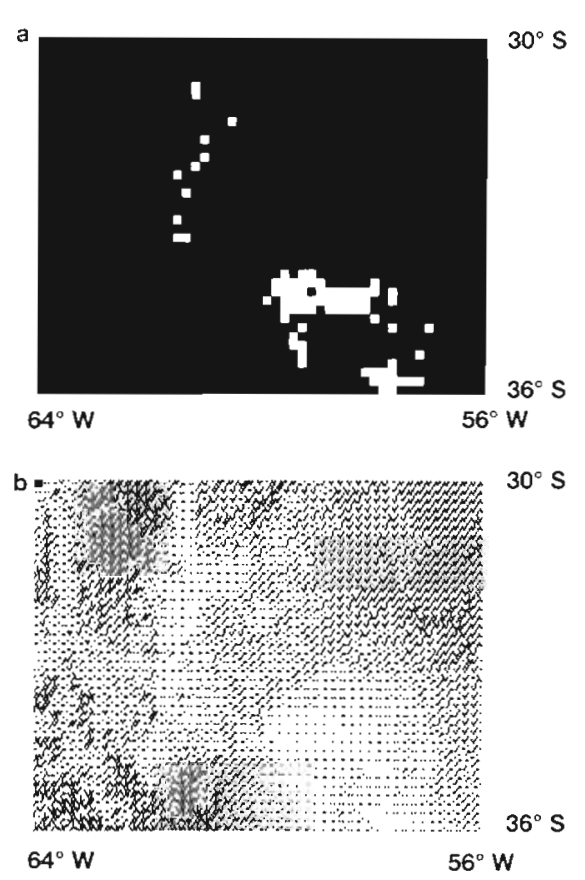

Fig. 11. (a) Rain area (white) as classified by discriminant analysis for 7 February 1993. (b) Infrared image for 7 February 1993, with higher values indicated by lighter areas

Table 5. Results obtained for dates in the verifying set on which rain occurred

\begin{tabular}{|rccc|}
\hline Date & POD $(\%)$ & FAR $(\%)$ & $f(\%)$ \\
\hline 6 Jan & 44 & 0 & 22 \\
14 Jan & 60 & 14 & 23 \\
21 Jan & 75 & 25 & 9 \\
7 Feb & 80 & 33 & 14 \\
12 Mar & 67 & 11 & 25 \\
\hline
\end{tabular}

used to recategorize the classes postulated by theoretical research. The results from the technique applied here, over a defined mid-latitude area of Argentina, were verified using records from ground synoptic and rain-gauge stations and compared with surface synoptic maps. Visual inspection of synoptic maps indicated that the technique performs better for convective rain. Even though this work is only a first step in objective identification of rainfall areas from satellite imagery in this country, it has been demonstrated that satisfactory results can be achieved. The technique was also found useful in distinguishing clear skies from clouds as well as in differentiating raining clouds from non-raining clouds. Such information could be useful for constructing regional rain and cloud climatologies, and for synoptic and agricultural applications.
Acknowledgements. I thank the authorities of the National Weather Service of Argentina, who graciously provided the satellite information, synoptic data and analysis and the meteorological gauge measurements. This study was supported by grants UBA-19095/91 and CONICET-PIA 07812/91

\section{LITERATURE CITED}

Barrett EC (1970) The estimation of monthly rainfall from satellite data. Mon Weather Rev 98:322-327

Barret EC (1973) Forecasting daily rainfall from satellite data. Mon Weather Rev 101:215-222

Barrett EC, Kidd C, Bailey JO (1987) The use of SMMR data in support of the Bristol/NOAA Interactive Scheme (BIAS) for satellite improved rainfall monitoring. Annual Report, US Department of Commerce

Barrett EC, Martin DW (1981) The use of satellite data in rainfall monitoring. Academic Press London.

Berger FH (1989) Cloud classes derived from AVHRR data. 4 th AVHRR Data User's Meeting. EUMESAT, Rothenburg. p 65-67

Davis J (1973) Statistics data analysis in geology. John Wiley and Sons, New York, p 442-472

Desbois M. Seze G, Szejwach G (1982) Automatic classification of clouds on METEOSAT imagery: application to high level clouds. J appl Meteorol 21:401-412

D'Souza G, Barrett EC, Power CH (1990) Satellite rainfall estimation techniques using visible and infrared imagery. Remote Sensing Rev 4:379-414

Eastman JR (1992) IDRISI 4.0. University Graduate School of Geography, Worcester, MA

Follansbee WA (1973) Estimation of averaged daily rainfall from satellite cloud photographs. NOAA Tech Mem NESS 44

González MH, Velasco I (1987) Factibility of evaluating rainfall in Argentina with satellite imagery. Preprint II of the Interamerican Congress of Meteorology 7.10.1. Centro Argentino de Meteorolgas, Buenos Aires (in Spanish)

Green PE (1978) Analyzing multivariate data, Chap 9. The Dryen Press, Hindale, II

Henderson-Sellers A (1984) Satellite sensing of a cloudy atmosphere, Chap 6. Taylor and Francis, London

Kilonsky BJ, Ramage CS (1976) A technique for estimating tropical open ocean rainfall from satellite observations. $J$ appl Meteorol 15:972-975

Negri AJ, Adler RF, Nelkin EJ, Huffman GJ (1994) Regional rainfall climatologies derived from special sensors microwaves imager (SSM/I) data. Bull Am Meteorol Soc 75(7):1165-1182

Phulpin $T$, Derrien M, Brard A (1983) A two dimensional histogram procedure to analyze cloud cover from NOAA satellite. J Clim appl Meteorol 22(8):1332-1345

Scofield R (1987) The Nesdis operational convective precipitation estimation technique. Mon Weather Rev 115: $1773-1792$

Scofield R, Oliver V (1977) A scheme for estimating convective rainfall from satellite imagery. NOAA. Tech Mem NESS 86

Seze G, Desbois M (1987) Cloud cover analysis from satellite imagery using spatial and temporal characteristics of the data. J Clim appl Meteorol 26:287-303

Spencer RW, Goodman HM, Hood RE (1989) Precipitating retrieval over land and ocean with the SSM/I: Identification and characteristics of the scattering signal. $J$ atmos ocean Tech 2:254-263

Tsonis AA (1984) On the separability of various classes from the GOES visible and infrared data. J Clim appl Meteorol 23:1393-1410 
Tsonis A.A (1988) Single thresholding and rain area delineation from satellite imagery. J appl Meteorol 27:1302-1306

Tsonis AA, Isaac GA (1985) On a new approach for instantaneous rain area delineation in midlatitudes using GOES data. J Clim appl Meteorol 24:1208-1218

Editor: V. Meentemeyer, Athens, Georgia, USA
Velasco 1, González MH (in press) Essay of a method for separating rainfall clouds using AVHRR images over Argentina. Proceeding of the VI Latinoamerican Symposium of Remote Sensing. Selper, Cartagena, Colombia (in Spanish)

Manuscript first received: October 15, 1994

Revised version accepted: June 28, 1995 